\title{
Commentary: A novel surgical approach for apical hypertrophic cardiomyopathy: A new tool in the armamentarium
}

\author{
Francis D. Pagani, MD, PhD
}

\author{
From the Department of Cardiac Surgery, University of Michigan, Ann Arbor, Mich. \\ Disclosures: Author has nothing to disclose with regard to commercial support. \\ Received for publication April 2, 2019; accepted for publication April 3, 2019; available ahead of print May 27, \\ 2019. \\ Address for reprints: Francis D. Pagani, MD, PhD, Otto Gago, MD Endowed Professor of Cardiac Surgery, Uni- \\ versity of Michigan, 5161 Cardiovascular Center, 1500 E Medical Center Dr, Ann Arbor, MI 48109 (E-mail \\ fpagani@umich.edu). \\ J Thorac Cardiovasc Surg 2020;159:153-4 \\ $0022-5223 / \$ 36.00$ \\ Copyright (c) 2019 by The American Association for Thoracic Surgery \\ https://doi.org/10.1016/j.jtcvs.2019.04.018
}

Apical hypertrophic cardiomyopathy (HCM) is a variant of HCM in which the hypertrophy of the myocardium predominantly involves the apex of the left ventricle, resulting in reduced left ventricular cavity size and in some cases midcavitary obstruction, as opposed to the left ventricular outflow tract obstruction typically seen in $\mathrm{HCM}^{1-4}$ Initially described in Japan, apical HCM has a high prevalence in the Asian population with HCM but is observed less frequently in non-Asian populations. ${ }^{1-4}$ Although apical HCM is generally thought to have a benign course, more recent observations have suggested that it is associated with increased mortality when compared with an age- and sex-matched general population, with age, female sex, and atrial fibrillation being important adverse prognostic characteristics. ${ }^{5}$ For patients with advanced symptoms not responsive to medical management, few surgical therapies, other than heart transplantation, achieve effective relief of symptoms.

In this issue of the Journal, Nguyen and colleagues ${ }^{6}$ from the Mayo Clinic in Rochester, Minnesota, describe a unique surgical cohort of 113 patients with advanced heart failure symptoms undergoing myectomy through an apical approach for treatment of apical variant HCM between September 1993 and March 2017. This cohort represented patients with advanced stages of symptoms, with 108 (96\%) classified with New York Heart Association class III or IV functional limitations. After myectomy through an apical approach, $76 \%$ of patients reported improvement in symptoms at last follow-up, with only 4 patients $(4 \%)$ dying within 30 days of operation and only 3 patients $(3 \%)$ requiring subsequent cardiac transplantation for recurrent heart failure. Importantly, in the last decade of the experience, there were no operative deaths. There were 19 late deaths, with estimated 1-, 5-, and 10-year survivals of $96 \%, 87 \%$, and $74 \%$, respectively. When compared with a national database of heart transplant recipients with a diagnosis of HCM, survival of the patient cohort

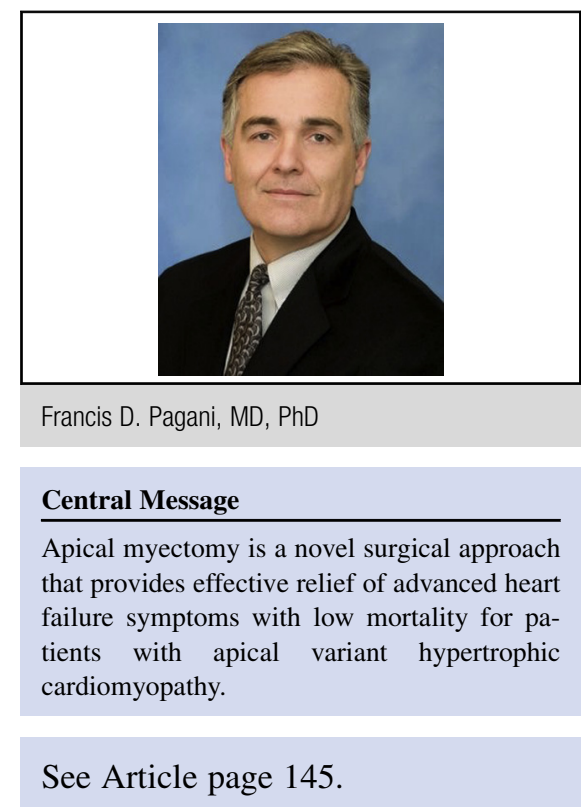

who underwent myectomy through an apical approach appeared superior to that of patients with HCM listed for heart transplant.

This recent report from the Mayo group expands on their initial description of the myectomy procedure through an apical approach ${ }^{7}$ and, importantly, establishes this surgical approach as a viable and important treatment option for patients with apical variant HCM. Although these data suggest a durable effect of the procedure for most candidates in terms of symptomatic benefit, the comparison with heart transplantation presented by Nguyen and colleagues ${ }^{6}$ is limited, because baseline characteristics of each cohort, other than age and sex, were not available for rigorous comparison. Further, despite improvement in symptoms, a significant number of patients continued to have advanced symptoms, and functional data on only $36 \%$ of the patients were available at a median follow-up of 5 years. More rigorous follow-up data with respect to functional outcomes are therefore needed, particularly when trying to make a strong comparison with heart transplantation. Further, improvements in surgical outcomes reported by Nguyen and colleagues ${ }^{6}$ were achieved on the basis of refinement of the surgical technique and patient selection. It would have been informative if Nguyen and colleagues ${ }^{6}$ had provided further insight into these important issues. 
Patients with the apical variant of HCM and advanced symptoms have represented a challenging subset of patients with HCM. Nguyen and colleagues ${ }^{6}$ have provided an alternative surgical approach for this group of patients that cautiously represents an innovative and effective treatment option.

\section{References}

1. Maron MS, Finley JJ, Bos JM, Hauser TH, Manning WJ, Haas TS, et al. Prevalence, clinical significance, and natural history of left ventricular apical aneurysms in hypertrophic cardiomyopathy. Circulation. 2008;118:1541-9.

2. Sakamoto T, Tei C, Murayama M, Ichiyasu H, Hada Y. Giant T wave inversion as a manifestation of asymmetrical apical hypertrophy (AAH) of the left ventricle. Echocardiographic and ultrasono-cardiotomographic study. Jpn Heart J. 1976;17:611-29.
3. Yamaguchi H, Ishimura T, Nishiyama S, Nagasaki F, Nakanishi S, Takatsu F, et al. Hypertrophic nonobstructive cardiomyopathy with giant negative T waves (apical hypertrophy): ventriculographic and echocardiographic features in 30 patients. Am J Cardiol. 1979;44:401-12.

4. Kitaoka H, Doi Y, Casey SA, Hitomi N, Furuno T, Maron BJ. Comparison of prevalence of apical hypertrophic cardiomyopathy in Japan and the United States. Am J Cardiol. 2003;92:1183-6.

5. Klarich KW, Attenhofer CH, Binder J, Binder J, Connolly HM, Scott CG, et al. Risk of death in long-term follow-up of patients with apical hypertrophic cardiomyopathy. Am J Card. 2013;111:1784-91.

6. Nguyen A, Schaff HV, Nishimura RA, Geske JB, Dearani JA, King KS, et al. Apical myectomy for patients with hypertrophic cardiomyopathy and advanced heart failure. J Thorac Cardiovasc Surg. 2020;159:145-52.

7. Schaff HV, Brown ML, Dearani JA, Abel MD, Ommen SR, Sorajja P, et al. Apical myectomy: a new surgical technique for management of severely symptomatic patients with apical hypertrophic cardiomyopathy. J Thorac Cardiovasc Surg. 2010; 139:634-40. 